\title{
Heavy Metal Induced Antibiotic Resistance in Bacterium LSJC7
}

\author{
Songcan Chen ${ }^{1, \dagger}$, Xiaomin Li ${ }^{1, \dagger}$, Guoxin Sun ${ }^{1, *}$, Yingjiao Zhang ${ }^{2}$, Jianqiang Su ${ }^{2}$ and Jun Ye ${ }^{2, *}$ \\ 1 State Key Lab of Urban and Regional Ecology, Research Center for Eco-Environmental Sciences, \\ Chinese Academy of Sciences, Beijing 100085, China; E-Mails: scchen@iue.ac.cn (S.C.); \\ xmli2013_st@rcees.ac.cn (X.L.) \\ 2 Key Lab of Urban Environment and Health, Institute of Urban Environment, \\ Chinese Academy of Sciences, Xiamen 361021, China; E-Mails: yjzhang@iue.ac.cn (Y.Z.); \\ jqsu@iue.ac.cn (J.S.) \\ $\dagger$ These authors contributed equally to this work. \\ * Authors to whom correspondence should be addressed; \\ E-Mails: gxsun@rcees.ac.cn (G.S.); jye@iue.ac.cn (J.Y.); \\ Tel.: +86-10-6284-9328 (G.S.); +86-592-619-0560 (J.Y.).
}

Academic Editor: Masato Matsuoka

Received: 5 September 2015 / Accepted: 21 September 2015 / Published: 29 September 2015

\begin{abstract}
Co-contamination of antibiotics and heavy metals prevails in the environment, and may play an important role in disseminating bacterial antibiotic resistance, but the selective effects of heavy metals on bacterial antibiotic resistance is largely unclear. To investigate this, the effects of heavy metals on antibiotic resistance were studied in a genome-sequenced bacterium, LSJC7. The results showed that the presence of arsenate, copper, and zinc were implicated in fortifying the resistance of LSJC7 towards tetracycline. The concentrations of heavy metals required to induce antibiotic resistance, i.e., the minimum heavy metal concentrations (MHCs), were far below (up to 64-fold) the minimum inhibition concentrations (MIC) of LSJC7. This finding indicates that the relatively low heavy metal levels in polluted environments and in treated humans and animals might be sufficient to induce bacterial antibiotic resistance. In addition, heavy metal induced antibiotic resistance was also observed for a combination of arsenate and chloramphenicol in LSJC7, and copper/zinc and tetracycline in antibiotic susceptible strain Escherichia coli DH5 $\alpha$. Overall, this study implies that heavy metal induced antibiotic resistance might be ubiquitous among various microbial species and suggests that it might
\end{abstract}


play a role in the emergence and spread of antibiotic resistance in metal and antibiotic co-contaminated environments.

Keywords: LSJC7; antibiotic; heavy metal; resistance

\section{Introduction}

Co-existence of heavy metals and antibiotics occurs in many kinds of environmental matrices, such as gastrointestinal tracts, animal manure and poultry farm sites [1-3]. For example, arsenic and antibiotics are commonly used as food supplements in the livestock industry for disease control and growth promotion [4], which makes the intestinal microbiota of the domestic animals co-exposed to arsenic and antibiotics [3]. Furthermore, the application of poultry manure as fertilizer to the soil, the desired practice for recycling nutrients $[5,6]$, causes the indigenous microorganisms to be exposed to arsenic as well as antibiotics [7]. Heavy metals are persistent in nature, accumulating in different components of the ecosystems [8]. Although many antibiotics have relatively short half-lives, they are regarded as "pseudopersistent" due to their continuous introduction into the ecosystem [5,9]. Such mixed contamination is causing considerable concerns, i.e., whether their effects are combined with regard to selective ability of antibiotic resistance is unclear $[10,11]$.

In some natural environments with microbial communities, combined contaminations of heavy metals and antibiotics contribute to the occurrence and spread of microbial antibiotic resistance; and sometimes multidrug resistance evolves [12]. For example, co-exposure to $\mathrm{Zn}$ and antibiotics such as oxytetracycline in activated sludge bioreactors appears to improve the resistance of the microbial community towards antibiotics [13]. The amendment of $\mathrm{Cu}$ in agricultural soils selects for $\mathrm{Cu}$ resistance and further co-selects for resistance to ampicillin, chloramphenicol and tetracycline [14]. Both $\mathrm{Ni}$ and $\mathrm{Cd}$ increased the frequency of bacterial resistance in microcosms to chemically unrelated antibiotics including ampicillin or chloramphenicol [15]. One possible explanation of such improvement of antibiotic resistance is that the presence of heavy metals enhanced the enrichment and growth of indigenous bacteria in the microbial community, which are already bearing antibiotic resistance genes; another possibility is that the resistance in bacteria which is sensitive to antibiotics could be induced due to the co-existence of heavy metals and antibiotics in the environment. Some investigations have demonstrated the positive correlation between the abundance of antibiotic resistance genes and the elevated concentrations of antibiotic and heavy metals in environments $[2,16]$. However, few reports are available about whether heavy metals could enhance the antibiotic resistance in the resistant bacteria or induce antibiotic resistance in sensitive bacteria [1].

Strain LSJC7, a Gram-negative member of the family Enterobacteriaceae in the order Enterobacteriales of the class Gammaproteobacteria, with dual resistance to arsenic and tetracycline, was previously isolated from an antimony tailing in China [17]. The whole genome of LSJC7 has been sequenced (AMFN00000000). This study systematically investigated the selective effects of heavy metal on antibiotic resistance in this strain, suggesting that bacterial antibiotic resistance could be induced by heavy metals. 


\section{Results and Discussion}

\subsection{Metal(loid) Resistance of LSJC7 and Identification of Putative Resistance Genes}

The resistance of LSJC7 to arsenate was at a very high level, up to $100 \mathrm{mM}$ in Luria-Bertani (LB) medium (Figure 1a); and the effective concentration of arsenate that caused a $90 \%$ of maximal growth inhibition ( $\mathrm{EC}_{90}$ ) was estimated to be $123 \mathrm{mM}$ (Figure 1b). The resistance of LSJC7 to arsenate was considerably higher than the reported arsenate resistant bacterium Geobacillus kaustophilus whose growth was completely prevented in the presence of $80 \mathrm{mM}$ arsenate in LB broth [18]. Such high level of arsenate resistance in LSJC7 could be due to two arsenical resistance gene clusters (arsRDABC and $\operatorname{arsRBC}$ ) in its bacterial chromosome (Table $\mathrm{S} 1$ ), which conferred arsenate resistance through arsenate reduction (arsenate reductase, ArsC) and active arsenite efflux (ArsB). Previous studies reported that bacteria expressing the arsRDABC operon were usually more resistant to arsenate than those expressing arsRBC operons because protein ArsA could form a complex with ArsB that catalyzes ATP-driven arsenite efflux [19], this might explain why LSJC7 possesses higher resistance to arsenate than G. kaustophilus which only contains arsRBC.

The resistance of LSJC7 towards other metals and metalloids were tested as well in this study. LSJC7 exhibited the highest resistance to $\mathrm{Cu}^{2+}$, while $\mathrm{Ag}^{+}$was the most toxic compared to the other metal ions (Figure 2a). The minimum inhibition concentrations (MICs) for $\mathrm{Cu}^{2+}, \mathrm{Zn}^{2+}, \mathrm{Cd}^{2+}, \mathrm{Cr}_{2} \mathrm{O}_{7}^{2-}$, and $\mathrm{Ag}^{+}$were 16, 10, 2.5, 1.6 and $0.25 \mathrm{mM}$ in LB medium, respectively. Various genes related to $\mathrm{Cu}^{2+}$, $\mathrm{Zn}^{2+}, \mathrm{Cd}^{2+}$, and $\mathrm{Cr}_{2} \mathrm{O}_{7}^{2-}$ resistances have been identified by analyzing annotated genome of LSJC7 (Table S1).

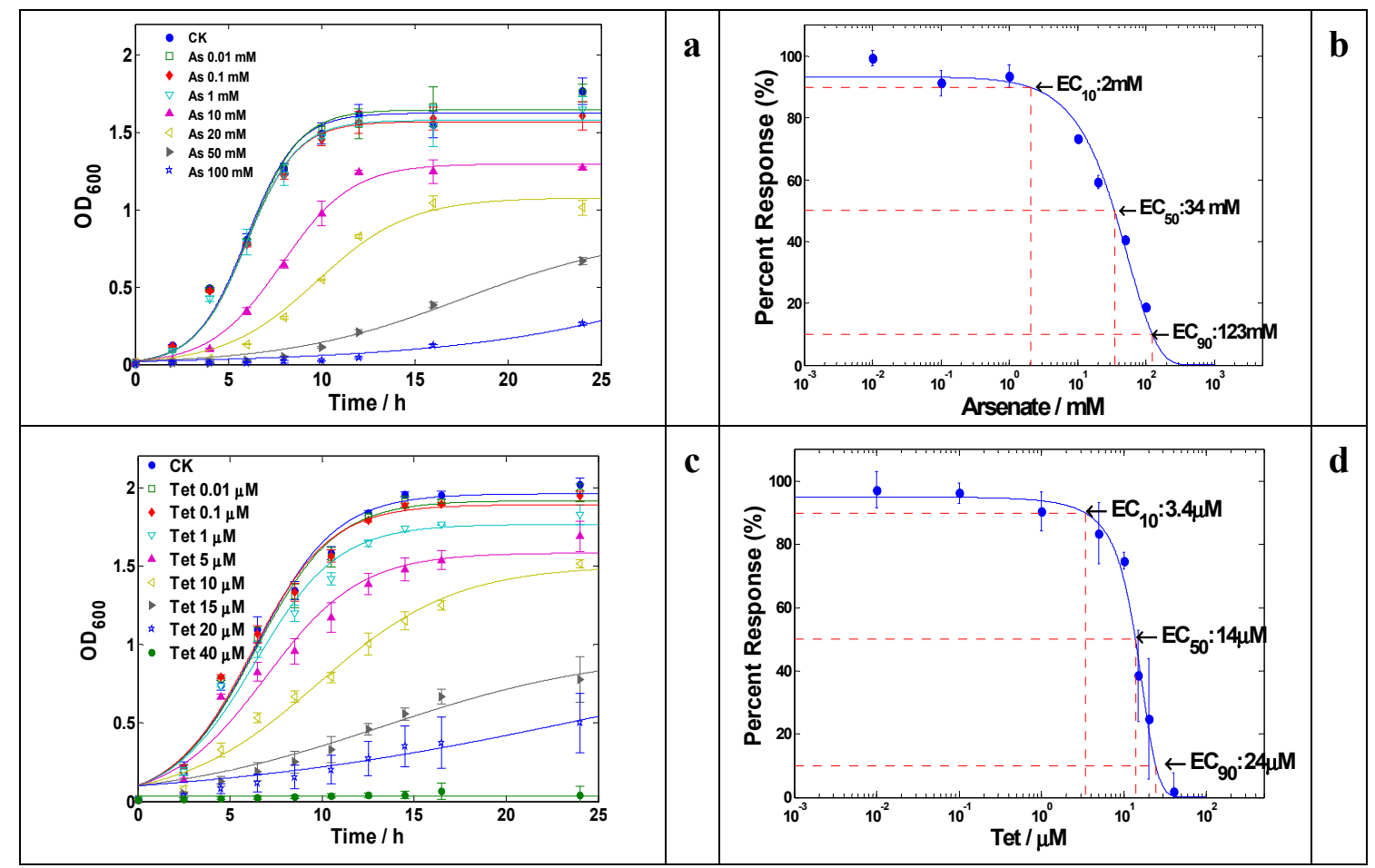

Figure 1. (a) Growth curves of LSJC7 with arsenate treatment; (b) Dose-response curve of LSJC7 with arsenate treatment; (c) Growth curves of LSJC7 with tetracycline treatment; (d) Dose-response curve of LSJC7 with tetracycline treatment. 


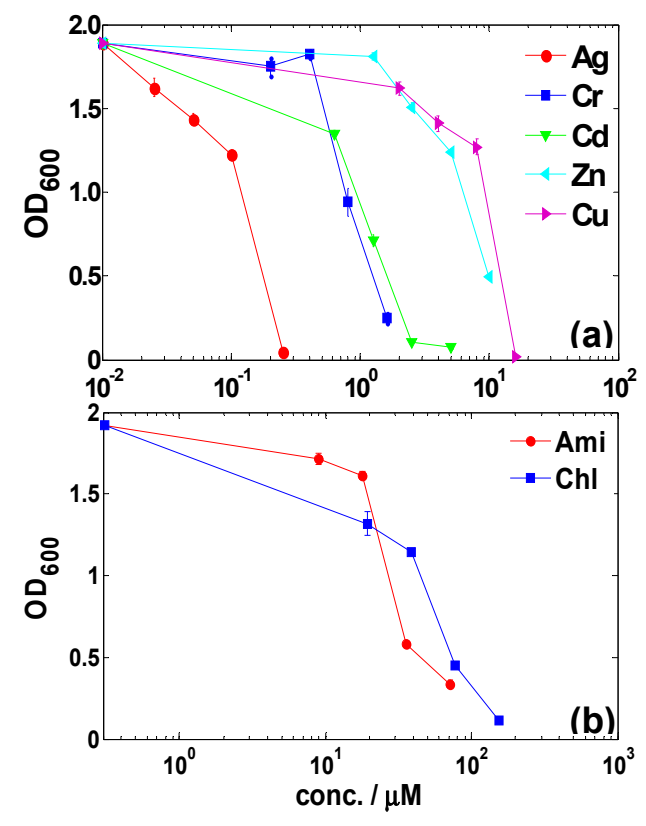

Figure 2. (a) Dose-response inhibitions of heavy metals on the growth of LSJC7; (b) Dose-response inhibitions of antibiotics on the growth of LSJC7. Ampicillin (Amp), chloramphenicol (Chl).

\subsection{Antibiotic Resistance of LSJC7 and Identification of Putative Resistance Genes}

Tetracycline resistance of LSJC7 was tested in this study. During the incubation period, LSJC7 could grow in the presence of $20 \mu \mathrm{M}$ (approx. $10 \mu \mathrm{g} \cdot \mathrm{mL}^{-1}$ ) tetracycline, while no viable cells were recovered at concentrations more than $40 \mu \mathrm{M}$ (Figure 1c); The calculated $\mathrm{EC}_{10}, \mathrm{EC}_{50}$, and $\mathrm{EC}_{90}$ values of tetracycline for LSJC7 were $3.4 \mu \mathrm{M}, 14 \mu \mathrm{M}$, and $24 \mu \mathrm{M}$, respectively (Figure 1d). Analysis of the annotated genome of LSJC7 revealed the presence of putative genes responsible for multiple layers of tetracycline resistance systems, including ribosomal protection protein (tetm, tetpb, otra), tetracycline efflux pump (otrb, tet39, tetb), and tetracycline modification enzyme (tet34)-like genes.

The resistance of LSJC7 to chloramphenicol and ampicillin was also evaluated. Results showed that the MICs of LSJC7 for chloramphenicol and ampicillin were slightly lower than $155 \mu \mathrm{M}$ (approximately $50 \mu \mathrm{g} \cdot \mathrm{mL}^{-1}$ ) and $72 \mu \mathrm{M}$ (approximately $25 \mu \mathrm{g} \cdot \mathrm{mL}^{-1}$ ), respectively (Figure $2 \mathrm{~b}$ ). As LSJC7 exhibited resistant to three classes of antimicrobial agents, it could be referred to as multi-resistant according to the definition given by Schwarz et al. [20]. Further analysis based on genomic inspection revealed that the multi-resistance phenotype of LSJC7 may be ascribed to the presence of specific resistance genes and multidrug resistance (MDR) determinants (e.g., multidrug efflux transporter) in the chromosome (Table S2). The broadness of antibiotic resistome in LSJC7 might be a reflection of powerful selection pressure in the environment such as antibiotics or even heavy metals [12].

\subsection{Enhancement of Antibiotic Resistance in the Presence of Heavy Metals}

The growth of LSCJ7 was significantly promoted in the presence of arsenate $(2 \mathrm{mM})$ and tetracycline $(24 \mu \mathrm{M})$ compared to the equivalent tetracycline treatment alone (Figure 3a), indicating 
that the existence of arsenate enhanced bacterial tetracycline resistance. Similarly, copper (4 mM) or zinc $(1.25 \mathrm{mM})$ could also increase tetracycline resistance in LSJC7 (Figure 3b,c). In contrast, the resistance of Pseudomonas oryzihabitans to tetracycline turned out to be decreased by the addition of arsenate, zinc, or copper (Figure 4).

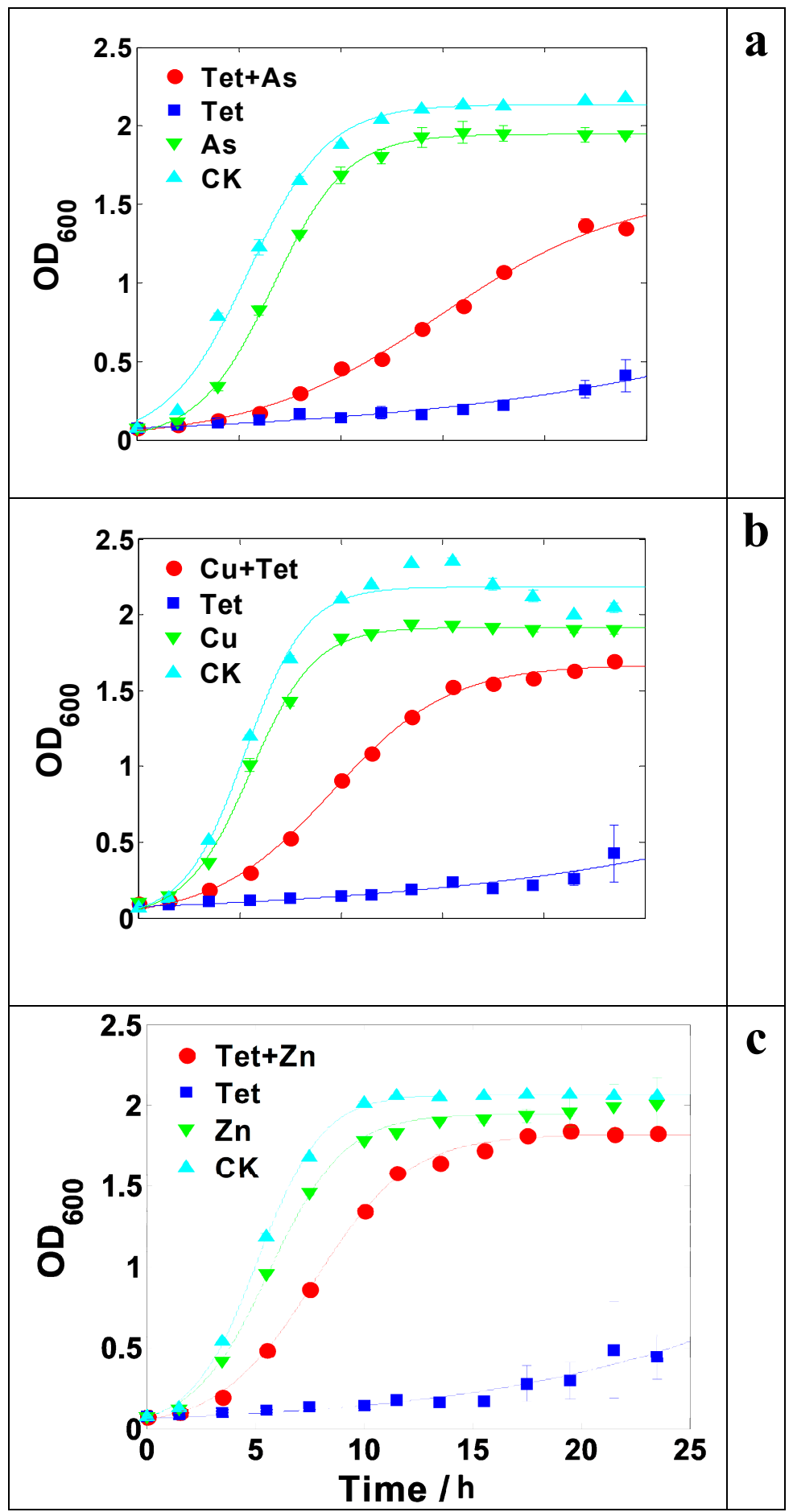

Figure 3. (a) Growth curve of LSCJ7 with $2 \mathrm{mM}$ arsenate (As) and/or $24 \mu \mathrm{M}$ tetracycline (Tet) treatment; (b) Growth curve of LSJC7 with $4 \mathrm{mM}$ copper $(\mathrm{Cu})$ and/or $24 \mu \mathrm{M}$ Tet treatment; (c) Growth curve of LSCJ7 with $1.25 \mathrm{mM}$ zinc (Zn) and/or $24 \mu \mathrm{M}$ Tet treatment. Each point is presented as mean $\pm \mathrm{SD}(n=3)$. Growth curves are fitted by logistic model. 

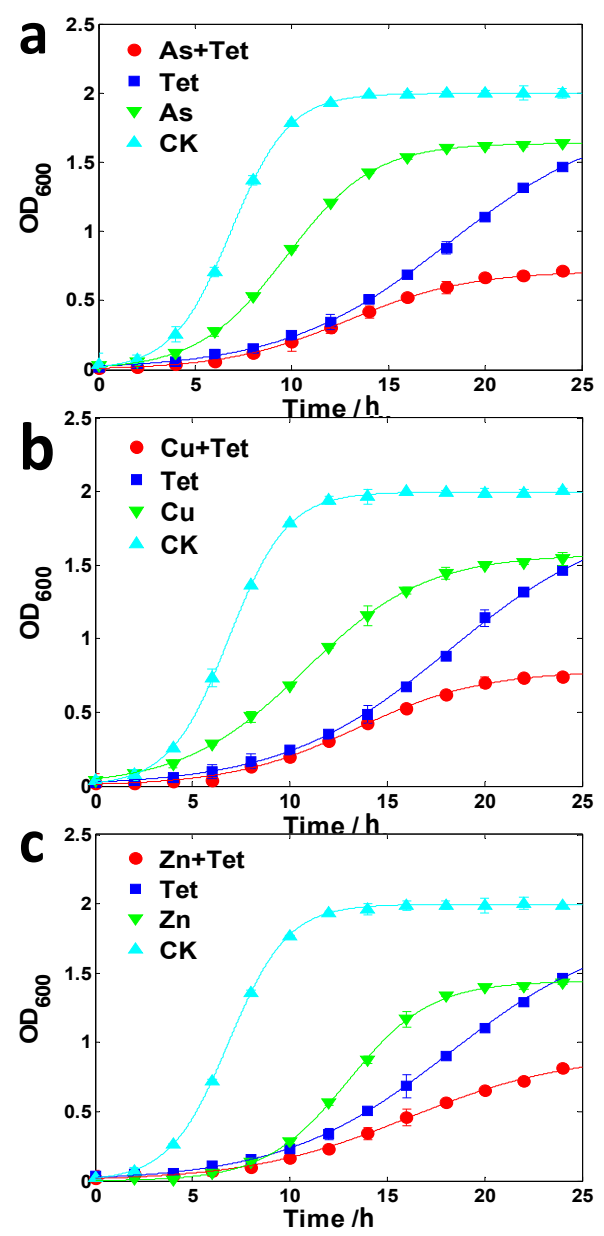

Figure 4. (a) Growth curve of Pseudomonas oryzihabitans with $2 \mathrm{mM}$ arsenate (As) and/or $2 \mu \mathrm{M}$ tetracycline (Tet) treatment; (b) Growth curve of $P$. oryzihabitans with $4 \mathrm{mM}$ copper $(\mathrm{Cu})$ and/or $2 \mu \mathrm{M}$ Tet treatment; (c) Growth curve of P. oryzihabitans with $5 \mathrm{mM}$ zinc $(\mathrm{Zn})$ and/or $2 \mu \mathrm{M}$ Tet treatment. Each point is presented as mean $\pm \mathrm{SD}(n=3)$. Growth curves are fitted by logistic model.

Heavy metal induced tetracycline resistance should be paid more attention. The concentration used here corresponds to $150 \mu \mathrm{g} \cdot \mathrm{mL}^{-1}$ arsenic and $12 \mu \mathrm{g} \cdot \mathrm{mL}^{-1}$ tetracycline, a level that has been found in many types of environments $[21,22]$. For example, both arsenic compound and tetracycline have been commonly used in large quantities as growth promotion agents in animal feed, mainly as roxarsone and p-arsanilic acid [23]. The level of organoarsenic and tetracycline in swine feed can be as high as 100 and $40 \mathrm{mg} \cdot \mathrm{kg}^{-1}$, respectively [6,24], which corresponds to a molar amount of arsenic and tetracycline approximately equal to the concentration used in this study. Thus, microbes present in animal intestines might be better equipped to survive under tetracycline pressure with the presence of arsenic, and hence have more opportunity to develop further mutations in genes encoding antibiotics resistance [25]. Furthermore, most of the organoarsenic and tetracycline are poorly absorbed by animals [23,26,27], and manure collected from feedlots has been shown to contain approximately $12 \mathrm{mg} \cdot \mathrm{kg}^{-1}$ of tetracycline and $110 \mathrm{mg} \cdot \mathrm{kg}^{-1}$ of arsenic coincidently [28]. With the common practice of using poultry and swine manure as fertilizers on agricultural lands, potentially significant amount of arsenic and tetracycline can be released into the soils and water together [29-31]. Moreover, copper or zinc could also increase tetracycline resistance in LSJC7 (Figure 3). This is problematic since these 
two kinds of metals are also widely applied in industries, agriculture, constructions, healthcare, and other areas from which they are released together with antibiotics into the environment $[32,33]$.

Different co-exposure levels of heavy metal and antibiotic were tested to identify the dose combinations for heavy metal induced antibiotic resistance in LSJC7. The results showed low-metal and high-antibiotic concentrations were prerequisite for heavy metal induced antibiotic resistance (Figure 5, Figures S1 and S2). (i) High levels $\left(>\mathrm{EC}_{50}\right)$ of antibiotic were required for heavy metal to exert stimulating effects on antibiotic resistance. As shown in Figure 5, at exposure equal or lower than $9 \mu \mathrm{M}$ tetracycline (EC50), the growth of LSJC7 was steadily reduced with increasing arsenate (copper or zinc) concentrations, which indicated that arsenic (copper or zinc) application could not enhance the resistance of LSJC7 to lower concentrations of tetracycline; (ii) Sub-toxic levels of heavy metal $\left(<\mathrm{EC}_{50}\right)$ were able to induce antibiotic resistance in LSJC7. Results showed that the minimum heavy metal concentrations (MHC) to induce antibiotic resistance in LSJC7 were significantly below the corresponding MICs (Figure 5): for arsenic and zinc, the MHC value was 1/64 of the MIC; for copper, the value was $1 / 16$. These values represent absolute heavy metal concentrations of $2 \mathrm{mM}$ (arsenate), $1 \mathrm{mM}$ (copper) and $0.16 \mathrm{mM}$ (zinc). In contrast, when arsenate (copper or zinc) was imposed at lethal concentration, fortification of tetracycline resistance disappeared in LSJC7 (Figure 5). This disappearance of fortification might be due to the overall metabolic dysfunction in LSJC7 caused by excessive arsenate (copper or zinc), as higher concentrations of heavy metals are toxic to microbes [34].

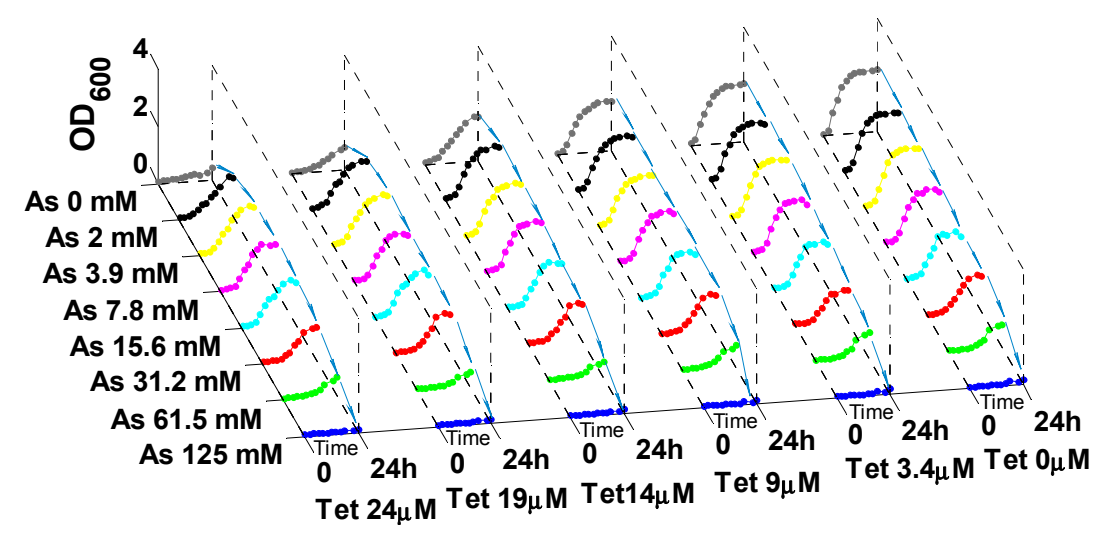

Figure 5. Growth curve of LSJC7 with tetracycline (Tet) and arsenate (As) co-treatment.

The fact that the concentrations of heavy metals required to induce antibiotic resistance lie well below (16- to 64-fold) the concentration necessary to prevent growth of bacteria is of great concern [35], since it indicates that even relatively small amount of heavy metal in the human body, with the concentration up to MHCs, could challenge antibiotic therapies. The risks of accumulating heavy metal to MHC levels in human body can be relatively high in some areas of the world. For example, cadmium contents in 3.3\% of rice samples were above maximum allowable concentration in China [36], where rice is the most important staple crop. Furthermore, there are large areas around the world where the groundwater naturally contains high levels of inorganic arsenic, such as in Bangladesh, where millions of people get their drinking water from wells containing up to $300 \mu \mathrm{g} \cdot \mathrm{L}^{-1}$ [37]. In addition, some countries and areas, such as United States, Singapore, China and Hong Kong, use traditional Chinese medicine (TCM) as preferred medical treatment, of which heavy metal contamination has been frequently reported [38]. Thus, people in these areas are more likely to accumulate heavy metals, 
and hence might become less sensitive to antibiotic treatment because of the antibiotic resistance induced by heavy metals.

In addition to arsenate (copper or zinc) induced tetracycline resistance in LSJC7, other combinations of heavy metals and antibiotics showed similar effects on bacterial antibiotic resistance (Table 1). Firstly, arsenate was capable to fortify the antibiotic resistance in LSJC7 other than tetracycline. Figure S3a showed that arsenate at $4 \mathrm{mM}$ could significantly alleviate the growth inhibition of chloramphenicol $(77 \mu \mathrm{M})$ on LSJC7. Moreover, Escherichia coli DH5 $\alpha$, a susceptible strain to tetracycline, had its resistance enhanced by $2 \mathrm{mM}$ copper or $0.625 \mathrm{mM}$ zinc (Figure S3). Mallik et al. [39] reported that clinical strains of Yersinia enterocolitica biovar 1A exhibited multiple antibiotic resistance induced by arsenite. In Pseudomonas aeruginosa, copper and zinc treatments caused resistance not only to metals but also to carbapenem antibiotics [40]. Escherichia hermannii and Enterobacter cloacae were shown to possess multidrug resistance induced by vanadium [41]. In all, our observations, combined with other studies, showed a broad distribution of antibiotic resistance induced by heavy metal among various microbial species, and implied heavy metal induced antibiotic resistance might play a role in maintenance and dissemination of antibiotic resistance at the sites co-contaminated with heavy metals and antibiotics.

Table 1. Summery of heavy metal mediated antibiotic resistance in LSJC7 and Escherichia coli DH5 $\alpha$.

\begin{tabular}{ccccccc}
\hline Strain & \multicolumn{3}{c}{ LSJC7 } & & \multicolumn{3}{c}{ E. coli DH5a } & \\
\hline Combination & Tet & Amp & Chl & Tet & Amp & Chl \\
\hline $\mathrm{As}$ & $*$ & $/$ & $*$ & $/$ & $/$ & $/$ \\
$\mathrm{Cu}$ & $*$ & $/$ & $/$ & $*$ & $/$ & $/$ \\
$\mathrm{Zn}$ & $*$ & $/$ & $/$ & $*$ & $/$ & $/$ \\
\hline
\end{tabular}

* indicates heavy metal mediated antibiotic resistance existed between two antimicrobial agents; / indicates heavy metal mediated antibiotic resistance did not exist between two antimicrobial agents.

\subsection{Possible Mechanisms of Heavy Metal Induced Antibiotic Resistance}

The expression of antibiotic resistance system in bacteria up-regulated by heavy metals might be responsible for the heavy metal enhanced antibiotic resistance (co-regulation). Several genes responsible for antibiotic resistance in LSJC7 were significantly up-regulated in the presence of arsenate (unpublished data). For example, a multiple antibiotic resistance gene, emrD (LSJC7GL004282), was up-regulated 1.6-fold in co-exposure to arsenate and tetracycline compared with that exposed to tetracycline alone, which might facilitate LSJC7 with higher antibiotic resistance in the presence of arsenate. In addition, compared with control, the expression of emrD and a tetracycline resistance gene, tet34 (LSJC7GL000047), were up-regulated by 3.8- and 2.7-fold, respectively, in the response to arsenate. These results suggested that the expression of antibiotic resistance genes could be modulated by arsenate, which subsequently increased the resistance to antibiotics.

Consistently, several other studies showed that the expression of bacterial antibiotic resistance systems could be induced by some heavy metals, resulting in enhanced antibiotic resistance. For example, the transcription of multi-drug (antibiotic) efflux pump genes acrD and $m d t A B C$ in Salmonella enterica, can be induced by a two-component signal transduction system BaeRS in 
response to copper or zinc (Figure 6), causing increased bacterial antibiotic resistance [42]. The multi-drug efflux pump AcrAB-TolC in E. coli (Figure 6), conferring resistance to diverse antibiotics, could be up-regulated by a global regulator SoxS in response to chromate or copper [43], which led to enhanced tolerance toward antibiotics [44]. Copper acted as an inducer to derepress multiple antibiotic resistance regulatory operon $\operatorname{mar} A A B$ in $E$. coli (Figure 6), causing enhanced bacterial antibiotic resistance [45]. As the genes mentioned above (baeRS, acrD, mdtABC, soxS, acrAB, tolC, marRAB) have been identified in the genome of LSJC7 (Table S3), we assumed that this regulatory network might provide a basic picture in controlling heavy metal induced antibiotic resistance in LSJC7 (Figure 6).

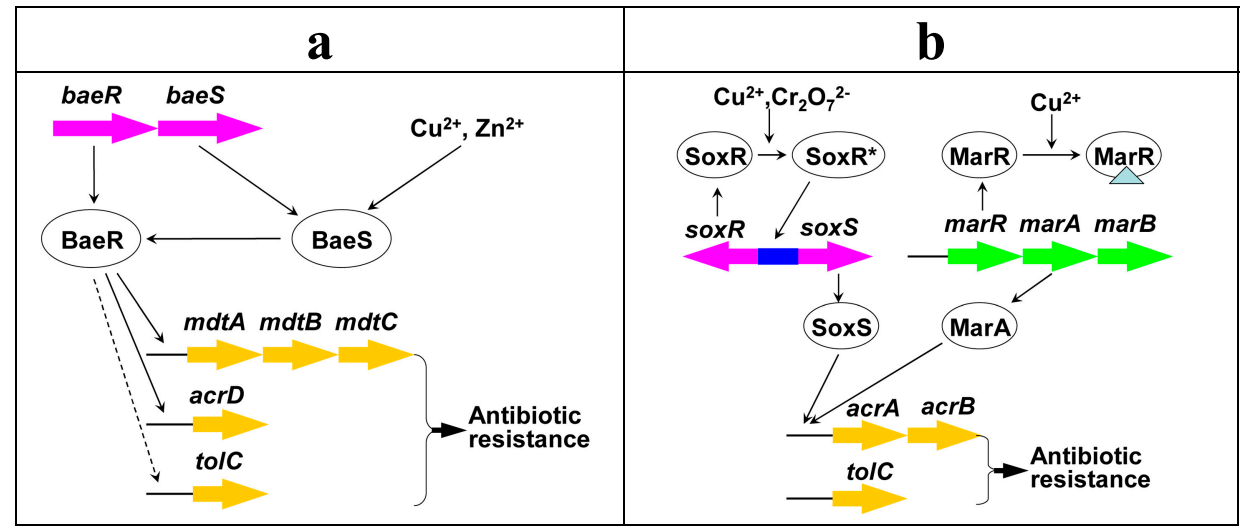

Figure 6. Possible mechanism (co-regulation) for heavy metal induced antibiotic resistance. (a) Pathway regulated by two-component signal transduction system BaeRS; (b) pathway regulated by global regulator SoxR or MarR. Identified or deduced pathways are represented as solid or dashed lines, respectively; the inducer of the repressor protein is represented as triangle; genes (gene clusters) are represented as colored arrows; * indicates the induced protein.

In addition, the chemical reactions between heavy metal and antibiotic might also lead to the phenomenon of bacterial cross-resistance. The effective concentrations of heavy metal and antibiotic may be affected by the chelation of antibiotics with metals to decrease the bioavailability of each other [46]. For example, the bioavailable tetracycline could be reduced by cationic ions such as copper (or zinc), due to the formation of complexes between metallic cations and tetracycline $[47,48]$. Therefore, the bacterial tetracycline resistance might be strengthened for the decreasing bioavailable concentration [48].

Antibiotic resistance induced by heavy metals reported in this study is alarming, although its exact mechanism remains unclear. In clinical settings, combination therapies involving silver and antibiotics have been suggested for treating Gram-negative infections [49]. However, our results indicated that precautions should be taken in such therapies, because co-treatment with heavy metals and antibiotics might induce antibiotic resistance in certain pathogenic bacteria and thus exacerbate infections [50]. In addition, combined use of heavy metals and antibiotics in intensive animal farming is still common and even unmonitored [2]. In such co-exposure systems, heavy metal induced antibiotic resistance might represent a novel antibiotic resistance mechanism [40] and could play a role in the maintenance and proliferation of antibiotic resistance reservoirs of clinically important microorganisms [12], which challenge life-saving antibiotic therapies [51]. 


\section{Experimental Section}

\subsection{Bacterial Strains and Growth Medium}

Strain LSJC7, a Gram-negative member of the family Enterobacteriaceae, was previously isolated in our laboratory. The strain was grown in LB medium ( $\mathrm{pH} 7.0 ; 10 \mathrm{~g} \mathrm{NaCl}, 5 \mathrm{~g}$ yeast extract, and $10 \mathrm{~g}$ tryptone in $1 \mathrm{~L}$ of double-distilled water).

\subsection{Dose-Response Inhibition of Growth for Heavy Metals}

Stock solutions of $\mathrm{CuSO}_{4} \cdot 5 \mathrm{H}_{2} \mathrm{O}, \mathrm{ZnSO}_{4} \cdot 7 \mathrm{H}_{2} \mathrm{O}, \mathrm{CdCl}_{2} \cdot 2 \mathrm{H}_{2} \mathrm{O}, \mathrm{AgNO}_{3}, \mathrm{Na}_{3} \mathrm{AsO}_{4}$, and $\mathrm{K}_{2} \mathrm{Cr}_{2} \mathrm{O}_{7}$ (Sinopharm Chemical, Zhonglian Chemical, Liaocheng, China) were prepared, respectively, in double-distilled water, passed through a $0.22 \mu \mathrm{m}$ syringe filter and stored at $4{ }^{\circ} \mathrm{C}$ until use.

The stock solution of heavy metal or metalloid oxyanion was diluted in LB broth followed by adjustment of the $\mathrm{pH}$ to 7.0, which served as working solution. The following concentrations of metals were chosen for working solution: $\mathrm{Cu}^{2+}, 16 \mathrm{mM} ; \mathrm{Zn}^{2+}, 10 \mathrm{mM}$; $\mathrm{Cd}^{2+}, 5 \mathrm{mM}$; $\mathrm{Ag}^{+}, 0.25 \mathrm{mM}$; $\mathrm{Cr}_{2} \mathrm{O}_{7}{ }^{2-}, 1.6 \mathrm{mM}$; and $\mathrm{AsO}_{4}{ }^{3-}, 100 \mathrm{mM}$. Serial twofold dilutions of the working solution were made in LB broth along the length of a 96-well microtiter plate (resulting in a serial concentration gradient from maximum concentration to minimum concentration). The first and last wells of every row were used as sterility and growth controls, respectively. Following $12 \mathrm{~h}$ exposure to heavy metals, the mean optical density at $600 \mathrm{~nm}\left(\mathrm{OD}_{600}\right)$ was measured by a microplate reader. Each heavy metal concentration was replicated in three wells.

\subsection{Dose-Response Inhibition of Growth for Antibiotics}

Stock solutions of tetracycline, ampicillin, or chloramphenicol (SolarBio, Beijing, China) were prepared in double-distilled water, passed through a $0.22 \mu \mathrm{m}$ syringe filter and stored at $-20{ }^{\circ} \mathrm{C}$ until use. The concentration of antibiotic added in LB broth as the working solution is 12,25 , and $50 \mu \mathrm{g} \cdot \mathrm{mL}^{-1}$ for tetracycline, ampicillin, and chloramphenicol, respectively. The following experimental procedure was the same as that described in the experiment with heavy metal exposure.

\subsection{Growth Kinetics of Bacteria}

Bacteria were grown overnight in LB medium at $37^{\circ} \mathrm{C}$, diluted 1:100, and re-grown in 96-well microtiter plates containing $200 \mu \mathrm{L} \mathrm{LB}$ media with different concentrations of heavy metals and/or antibiotics in each well (the concentrations of heavy metal and antibiotic were chosen according to dose-response curve). Then these membrane-sealed microtiter plates were incubated at $30{ }^{\circ} \mathrm{C}$ on a shaker for $24 \mathrm{~h}$ with agitation of $200 \mathrm{rpm}$. The growth kinetics of the cells were monitored by measuring $\mathrm{OD}_{600}$ every two hours using a Thermomax microplate reader with SoftMax Pro data-analysis software (Molecular Devices, Sunnyvale, CA, USA). In order to calibrate the results measured by microplate reader to $\mathrm{OD}_{600}$ detected by Spectrometer (light path length was fixed to $1 \mathrm{~cm}$ ), the linear relationship between microplate reader and Spectrometer has been established for data normalization. 


\subsection{Metal and Antibiotic Analysis}

Inductively coupled plasma-optical emission spectrometry (ICP-OES; Optima 8300 DV (PerkinElmer, Waltham, MA, USA)) was used to determine the concentrations of As, $\mathrm{Cd}, \mathrm{Cu}, \mathrm{Zn}, \mathrm{Ag}$, and $\mathrm{Cr}$ in $\mathrm{LB}$ culture media without any bacterium at the initial $(0 \mathrm{~h})$ time. The aliquots $(0.5 \mathrm{~mL}$ each $)$ were diluted and acidified using $1 \% \mathrm{HNO}_{3}$ to $50 \mathrm{~mL}$ in the tubes before measurement. The concentrations of tetracycline, ampicillin, and chloramphenicol in LB culture media were determined by liquid chromatography in combination with tandem mass spectrometry (LC-MS/MS; ABI 3200 Q TRAP (SCIEX, Arcade, NY, USA)), following described methods [52]. No significant differences were found between the nominal and measured exposure concentrations of heavy metals or antibiotics. Therefore, throughout the present study, nominal concentrations were used for data analysis.

\subsection{Data Analysis}

Dose-response inhibition of cells (treated with arsenate or tetracycline) and all growth kinetics were modeled by fitting a logistic function as shown in the following equation:

$$
y=\frac{a}{1+b e^{-c x}}
$$

where $y$ represents $\mathrm{OD}_{600} ; x$ represents the concentration of antibiotics or growth time, in dose-response inhibition curve or growth kinetics curve, respectively; $a, b$, and $c$ represent the regression coefficients. Data analysis and graphing of the experimental results were completed by EXCEL2003 and MATLAB2012a software.

\section{Conclusions}

In conclusion, this study revealed that the existence of heavy metals could enhance bacterial tetracycline resistance. Even heavy metals at sub-toxic levels were shown to induce bacterial antibiotic resistance, and such inducible antibiotic resistance might be ubiquitous among various microbial species in the environment. The fact that bacterial antibiotic resistance could be enhanced by heavy metals should be highlighted, as it might pose risks to environment and public health.

\section{Supplementary Materials}

Supplementary materials can be found at http://www.mdpi.com/1422-0067/16/10/23390/s1.

\section{Acknowledgments}

This work was financially supported by the National Natural Science Foundation of China (21210008) and State Key Program of Natural Science Foundation of China (No. 41430858). We thank Professor Yong-Guan Zhu for the valuable comments. 


\section{Author Contributions}

Songcan Chen and Xiaomin $\mathrm{Li}$ performed the experiments and drafted the manuscript. Yingjiao Zhang and Jianqiang Su participated in the design of the study. Guoxin Sun and Jun Ye supervised the study and revised the paper. All authors read and approved the final manuscript.

\section{Conflicts of Interest}

The authors declare no conflict of interest.

\section{References}

1. Martinez, J.L.; Rojo, F. Metabolic regulation of antibiotic resistance. FEMS Microbiol. Rev. 2011, 35, 768-789.

2. Zhu, Y.G.; Johnson, T.A.; Su, J.Q.; Qiao, M.; Guo, G.X.; Stedtfeld, R.D.; Hashsham, S.A.; Tiedje, J.M. Diverse and abundant antibiotic resistance genes in Chinese swine farms. Proc. Natl. Acad. Sci. USA 2013, 110, 3435-3440.

3. Looft, T.; Johnson, T.A.; Allen, H.K.; Bayles, D.O.; Alt, D.P.; Stedtfeld, R.D.; Sul, W.J.; Stedtfeld, T.M.; Chai, B.L.; Cole, J.R.; et al. In-feed antibiotic effects on the swine intestinal microbiome. Proc. Natl. Acad. Sci. USA 2012, 109, 1691-1696.

4. Hvistendahl, M. China takes aim at rampant antibiotic resistance. Science 2012, 336, 795-795.

5. Pan, X.; Qiang, Z.M.; Ben, W.W.; Chen, M.X. Residual veterinary antibiotics in swine manure from concentrated animal feeding operations in Shandong Province, China. Chemosphere 2011, 84, 695-700.

6. Wang, P.L.; Zhao, G.L.; Tian, J.; Su, X.O. High-performance liquid chromatography inductively coupled plasma mass spectrometry based method for the determination of organic arsenic feed additives and speciation of anionic arsenics in animal feed. J. Agric. Food Chem. 2010, 58, 5263-5270.

7. Binh, C.T.T.; Heuer, H.; Kaupenjohann, M.; Smalla, K. Piggery manure used for soil fertilization is a reservoir for transferable antibiotic resistance plasmids. FEMS Microbiol. Ecol. 2008, 66, 25-37.

8. Lu, X.; Gao, Y.; Luo, J.; Yan, S.H.; Rengel, Z.; Zhang, Z.H. Interaction of veterinary antibiotic tetracyclines and copper on their fates in water and water hyacinth (Eichhornia crassipes). J. Hazard. Mater. 2014, 280, 389-398.

9. Hernando, M.D.; Mezcua, M.; Fernandez-Alba, A.R.; Barcelo, D. Environmental risk assessment of pharmaceutical residues in wastewater effluents, surface waters and sediments. Talanta 2006, 69, 334-342.

10. Skurnik, D.; Ruimy, R.; Ready, D.; Ruppe, E.; Bernede-Bauduin, C.; Djossou, F.; Guillemot, D.; Pier, G.B.; Andremont, A. Is exposure to mercury a driving force for the carriage of antibiotic resistance genes? J. Med. Microbiol. 2010, 59, 804-807.

11. Kong, W.D.; Zhu, Y.G.; Fu, B.J.; Marschner, P.; He, J.Z. The veterinary antibiotic oxytetracycline and $\mathrm{Cu}$ influence functional diversity of the soil microbial community. Environ. Pollut. 2006, 143, 129-137. 
12. Baker-Austin, C.; Wright, M.S.; Stepanauskas, R.; McArthur, J.V. Co-selection of antibiotic and metal resistance. Trends Microbiol. 2006, 14, 176-182.

13. Peltier, E.; Vincent, J.; Finn, C.; Graham, D.W. Zinc-induced antibiotic resistance in activated sludge bioreactors. Water Res. 2010, 44, 3829-3836.

14. Berg, J.; Tom-Petersen, A.; Nybroe, O. Copper amendment of agricultural soil selects for bacterial antibiotic resistance in the field. Lett. Appl. Microbiol. 2005, 40, 146-151.

15. Stepanauskas, R.; Glenn, T.C.; Jagoe, C.H.; Tuckfield, R.C.; Lindell, A.H.; King, C.J.; McArthur, J.V. Coselection for microbial resistance to metals and antibiotics in freshwater microcosms. Environ. Microbiol. 2006, 8, 1510-1514.

16. Knapp, C.W.; McCluskey, S.M.; Singh, B.K.; Campbell, C.D.; Hudson, G.; Graham, D.W. Antibiotic resistance gene abundances correlate with metal and geochemical conditions in archived Scottish soils. PLOS ONE 2011, 6, e27300.

17. Su, J.Q.; Ye, J.; Zhu, Y.G. Draft genome sequence of a novel bacterial strain, LSJC7, belonging to the family Enterobacteriaceae with dual resistance to arsenic and tetracycline. J. Bacteriol. 2012, 194, 7005-7006.

18. Cuebas, M.; Sannino, D.; Bini, E. Isolation and characterization of an arsenic resistant Geobacillus kaustophilus strain from geothermal soils. J. Basic Microb. 2011, 51, 364-371.

19. Lin, Y.F.; Yang, J.B.; Rosen, B.P. ArsD: An As(III) metallochaperone for the ArsAB As(III)-translocating ATPase. J. Bioenerg. Biomembr. 2007, 39, 453-458.

20. Schwarz, S.; Silley, P.; Simjee, S.; Woodford, N.; van Duijkeren, E.; Johnson, A.P.; Gaastra, W. Editorial: Assessing the antimicrobial susceptibility of bacteria obtained from animals. J. Antimicrob. Chemother. 2010, 65, 601-604.

21. Hill, G.M.; Cromwell, G.L.; Crenshaw, T.D.; Dove, C.R.; Ewan, R.C.; Knabe, D.A.; Lewis, A.J.; Libal, G.W.; Mahan, D.C.; Shurson, G.C.; et al. Growth promotion effects and plasma changes from feeding high dietary concentrations of zinc and copper to weanling pigs (regional study). J. Anim. Sci. 2000, 78, 1010-1016.

22. Katouli, M.; Melin, L.; Jensen-Waern, M.; Wallgren, P.; Mollby, R. The effect of zinc oxide supplementation on the stability of the intestinal flora with special reference to composition of coliforms in weaned pigs. J. Appl. Microbiol. 1999, 87, 564-573.

23. Liu, X.P.; Zhang, W.F.; Hu, Y.N.; Hu, E.D.; Xie, X.D.; Wang, L.L.; Cheng, H.F. Arsenic pollution of agricultural soils by concentrated China animal feeding operations (CAFOs). Chemosphere 2015, 119, 273-281.

24. Granados-Chinchilla, F.; Rodriguez, C. Bioavailability of in-feed tetracyclines is influenced to a greater extent by crude protein rather than calcium. Anim. Feed Sci. Technol. 2014, 198, 323-332.

25. Webber, M.A.; Piddock, L.J.V. The importance of efflux pumps in bacterial antibiotic resistance. J. Antimicrob. Chemother. 2003, 51, 9-11.

26. Qiao, M.; Chen, W.D.; Su, J.Q.; Zhang, B.; Zhang, C. Fate of tetracyclines in swine manure of three selected swine farms in China. J. Environ. Sci. 2012, 24, 1047-1052.

27. Alcock, R.E.; Sweetman, A.; Jones, K.C. Assessment of organic contaminant fate in waste water treatment plants I: Selected compounds and physicochemical properties. Chemosphere 1999, 38, $2247-2262$. 
28. Ji, X.L.; Shen, Q.H.; Liu, F.; Ma, J.; Xu, G.; Wang, Y.L.; Wu, M.H. Antibiotic resistance gene abundances associated with antibiotics and heavy metals in animal manures and agricultural soils adjacent to feedlots in Shanghai; China. J. Hazard. Mater. 2012, 235, 178-185.

29. Garbarino, J.R.; Bednar, A.J.; Rutherford, D.W.; Beyer, R.S.; Wershaw, R.L. Environmental fate of roxarsone in poultry litter. I. Degradation of roxarsone during composting. Environ. Sci. Technol. 2003, 37, 1509-1514.

30. Ghosh, S.; LaPara, T.M. The effects of subtherapeutic antibiotic use in farm animals on the proliferation and persistence of antibiotic resistance among soil bacteria. ISME J. 2007, 1, 191-203.

31. Pruden, A.; Arabi, M.; Storteboom, H.N. Correlation between upstream human activities and riverine antibiotic resistance genes. Environ. Sci. Technol. 2012, 46, 11541-11549.

32. Wei, B.G.; Yang, L.S. A review of heavy metal contaminations in urban soils, urban road dusts and agricultural soils from China. Microchem. J. 2010, 94, 99-107.

33. Finley, R.L.; Collignon, P.; Larsson, D.G.J.; McEwen, S.A.; Li, X.Z.; Gaze, W.H.; Reid-Smith, R.; Timinouni, M.; Graham, D.W.; Topp, E. The scourge of antibiotic resistance: The important role of the environment. Clin. Infect. Dis. 2013, 57, 704-710.

34. Nies, D.H. Microbial heavy-metal resistance. Appl. Microbiol. Biotechnol. 1999, 51, 730-750.

35. Gullberg, E.; Albrecht, L.M.; Karlsson, C.; Sandegren, L.; Andersson, D.I. Selection of a multidrug resistance plasmid by sublethal levels of antibiotics and heavy metals. MBio 2014, 5, e01918-14, doi:10.1128/mBio.01918-14.

36. Fang, Y.; Sun, X.Y.; Yang, W.J.; Ma, N.; Xin, Z.H.; Fu, J.; Liu, X.C.; Liu, M.; Mariga, A.M.; Zhu, X.F.; et al. Concentrations and health risks of lead, cadmium, arsenic, and mercury in rice and edible mushrooms in China. Food Chem. 2014, 147, 147-151.

37. Smith, A.H.; Lingas, E.O.; Rahman, M. Contamination of drinking-water by arsenic in Bangladesh: A public health emergency. Bull. World Health Organ. 2000, 78, 1093-1103.

38. Harris, E.S.J.; Cao, S.G.; Littlefield, B.A.; Craycroft, J.A.; Scholten, R.; Kaptchuk, T.; Fu, Y.L.; Wang, W.Q.; Liu, Y.; Chen, H.B.A.; et al. Heavy metal and pesticide content in commonly prescribed individual raw Chinese Herbal Medicines. Sci. Total Environ. 2011, 409, 4297-4305.

39. Mallik, S.; Virdi, J.S.; Johri, A.K. Proteomic analysis of arsenite-Mediated multiple antibiotic resistance in Yersinia enterocolitica biovar 1A. J. Basic Microb. 2012, 52, 306-313.

40. Caille, O.; Rossier, C.; Perron, K. A copper-activated two-component system interacts with zinc and imipenem resistance in Pseudomonas aeruginosa. J. Bacteriol. 2007, 189, 4561-4568.

41. Hernandez, A.; Mellado, R.P.; Martinez, J.L. Metal accumulation and vanadium-induced multidrug resistance by environmental isolates of Escherichia hermannii and Enterobacter cloacae. Appl. Environ. Microbiol. 1998, 64, 4317-4320.

42. Nishino, K.; Nikaido, E.; Yamaguchi, A. Regulation of multidrug efflux systems involved in multidrug and metal resistance of Salmonella enterica serovar typhimurium. J. Bacteriol. 2007, 189, 9066-9075.

43. Harrison, J.J.; Tremaroli, V.; Stan, M.A.; Chan, C.S.; Vacchi-Suzzi, C.; Heyne, B.J.; Parsek, M.R.; Ceri, H.; Turner, R.J. Chromosomal antioxidant genes have metal ion-specific roles as determinants of bacterial metal tolerance. Environ. Microbiol. 2009, 11, 2491-2509. 
44. Okusu, H.; Ma, D.; Nikaido, H. AcrAB efflux pump plays a major role in the antibiotic resistance phenotype of Escherichia coli multiple-antibiotic-resistance (Mar) mutants. J. Bacteriol. 1996, 178, 306-308.

45. Hao, Z.Y.; Lou, H.B.; Zhu, R.F.; Zhu, J.H.; Zhang, D.M.; Zhao, B.X.S.; Zeng, S.Z.; Chen, X.; Chan, J.; He, C.; et al. The multiple antibiotic resistance regulator MarR is a copper sensor in Escherichia coli. Nat. Chem. Biol. 2014, 10, U21-U48.

46. Zhou, Y.; Xu, Y.B.; Xu, J.X.; Zhang, X.H.; Xu, S.H.; Du, Q.P. Combined toxic effects of heavy metals and antibiotics on a Pseudomonas fluorescens strain ZY2 isolated from swine wastewater. Int. J. Mol. Sci. 2015, 16, 2839-2850.

47. Zhang, Z.Y.; Sun, K.; Gao, B.; Zhang, G.X.; Liu, X.T.; Zhao, Y. Adsorption of tetracycline on soil and sediment: Effects of $\mathrm{pH}$ and the presence of $\mathrm{Cu}(\mathrm{II})$. J. Harzad. Mater. 2011, 190, 856-862.

48. Tong, F.; Zhao, Y.P.; Gu, X.Y.; Gu, C.; Lee, C.C.C. Joint toxicity of tetracycline with copper(II) and cadmium(II) to Vibrio fischeri: Effect of complexation reaction. Ecotoxicology 2015, 24, 346-355.

49. Morones-Ramirez, J.R.; Winkler, J.A.; Spina, C.S.; Collins, J.J. Silver enhances antibiotic activity against gram-negative bacteria. Sci. Transl. Med. 2013, 5, 190ra81, doi:0.1126/scitranslmed.3006276.

50. Vaun McArthur, J.; Tuckfield, R.C.; Baker-Austin, C. Antimicrobial Textiles. In Handbook of Experimental Pharmacology; Anthony, R.M.C., Eds; Springer: Berlin, Germany; Heidelberg, Germany, 2012; Volume 211, pp. 135-152.

51. Arias, C.A.; Murray, B.E. Antibiotic-resistant bugs in the 21st century-A clinical super-challenge. N. Engl. J. Med. 2009, 360, 439-443.

52. Zhang, D.D.; Lin, L.F.; Luo, Z.X.; Yan, C.Z.; Zhang, X. Occurrence of selected antibiotics in Jiulongjiang River in various seasons, South China. J. Environ. Monit. 2011, 13, 1953-1960.

(C) 2015 by the authors; licensee MDPI, Basel, Switzerland. This article is an open access article distributed under the terms and conditions of the Creative Commons Attribution license (http://creativecommons.org/licenses/by/4.0/). 